Revue internationale de l'économie sociale

Recma

Propos d'actualité et d'inactualité, 1887-1931 "Les œuvres de Charles Gide ", vol. XII. Comité pour l'édition des œuvres de Charles Gide. Paris, L'Harmattan, 2008

\title{
Hugues Puel
}

Numéro 312, mai 2009

URI : https://id.erudit.org/iderudit/1020942ar

DOI : https://doi.org/10.7202/1020942ar

Aller au sommaire du numéro

Éditeur(s)

Association Recma

ISSN

1626-1682 (imprimé)

2261-2599 (numérique)

Découvrir la revue

Citer ce compte rendu

Puel, H. (2009). Compte rendu de [Propos d'actualité et d'inactualité, 1887-1931

"Les œuvres de Charles Gide », vol. XII. Comité pour l'édition des œuvres de

Charles Gide. Paris, L’Harmattan, 2008]. Revue internationale de l'économie

sociale, (312), 107-108. https://doi.org/10.7202/1020942ar d'utilisation que vous pouvez consulter en ligne.

https://apropos.erudit.org/fr/usagers/politique-dutilisation/ 
«idéal ». M ais bien sûr, au premier abord, nous sommes tentés de penser l'inverse en raison de deux éléments contraires à notre image traditionnelle de la démocratie. Le premier est qu'il s'agit d'une démocratie de petits patrons dont certains sont multimillionnaires. Cette démocratie corporatiste est avant tout orientée vers I'accroissement des gains de ses membres et son succès tient en grande partie à son efficacité instrumentale par rapport aux autres réseaux de distribution. Elle constitue en effet un avantage comparatif très important favorisant l'innovation et sa diffusion: de nombreuses « expérimentations de terrain » des adhérents ont ensuite été reprises dans l'ensemble du mouvement (carte de fidélité Leclerc, nouveaux « concepts » de magasins... . .

Le second élément est que l'on est en présence d'une personnalisation extrême de nature «dynastique ", alors même que la liberté des adhérents est mise en avant et cela notamment dans les périodes de crise. La scission avec Intermarché est éclairante, le projet poursuivi par JeanPierre Le Roch (fondateur du groupe des Ex à I'origine du groupe des M ousquetaires) avait été celui d'une plus grande intégration, garant d'une meilleure efficacité économique. La position de Leclerc a été de valoriser l'indépendance des membres, même si l'évolution récente des deux grands groupes de distribution a eu tendance à les rapprocher. Le chapitre « $D$ es adhérents sous contrôle » confirme ce point, de la mise en évidenced'un système de droits de propriété dont $M$ arie-Laure Baron a bien souligné qu'il laissait libre la sortie de l'adhérent, mais pas celle des actifs investis(5).

Leclerc n'est pas une république, c'est plutôt une monarchie élective constitutionnelle, dont le président a été réélu en 2003 pour un nouveau mandant de quinze ans (!). D ans ce cadre, la succession, comme le soulève l'auteur, est un problème: M ichel-Edouard Leclerc, qui au-delà de

(5) Le pacte de préférence est ainsi le dispositif de verrouillage du réseau Leclerc en stipulant que, si un adhérent souhaite vendre son magasin, il doit le proposer en premier lieu à des adhérents et en second lieu au mouvement (qui dispose d'un droit de préemption). son nom a acquis par ses propres compétences de communicant et de gestionnaire une légitimité auprès des «barons » du mouvement, aura 66 anslors du prochain couronnement, en 2018.

Damien Rousselière

\section{Propos d'actualité et d'inactualité, 1887-1931}

«Les œuvres de Charles Gide», vol. XII. Comité pour l'édition des œuvres de Charles Gide. Paris, L'Harmattan, 2008.

Avec ce douzième volume s'achève cette remarquable édition des œuvres deC harles Gide. II est présenté par M arc Pénin, auteur d'une biographie de l'économiste parue en 1998 en introduction de cette édition dont il fut le maître d'œuvre soutenu par André Chomel, ancien dirigeant du C rédit coopératif et président dela fondation de cette banque.

La première partie de l'ouvrage comprend des « miettes d'actualité ». Ce sont des textes courts publiés entre 1887 et 1927 dans les revues auxquelles l'auteur avait coutume de participer: la Revued'économie politique, qu'il avait fondée, des revues de son engagement de chrétien réformé, Le H uguenot et $\mathrm{Foi}$ et $\mathrm{Vie}$, des publications d'intérêt général comme La Semaine littéraire et surtout L'Emancipation. L'actualité de l'époque y rejoint la nôtre: le racismeà l'encontre des travailleurs d'origine étrangère, la place du machinisme et de la technique, les rapports avec la Chine, lesens d'un nouveau sièclequi commence, la diversification des formes d'énergie, les relations avec l'Allemagne, les grèveset les problèmes sociaux, les problèmes monétaires.

La deuxième partie rassemble des contributions plus substantielles de l'économiste de $N$ îmes. Le premier texte date de 1888 et est intitulé "Lesillusions du progrès». II débat d'un thème récurrent de l'auteur autour du machinisme et du sens du progrès technique, au sujet duquel il émet des doutes: « Le progrès actuel n'est pas si grand qu'on le dit; le progrès futur n'est pas si sûr qu'on lepense» (p. 130). Ce thèmesera repris après la Seconde Guerre mondiale par un autre 
protestant, Jacques Ellul, professeur à Bordeaux, qui sen feral'avocat à charge. Le deuxième texte est la traduction d'un article qui n'avait jamais paru en français et que la revueaméricainePolitical Science Q uaterly avait publié en 1890 . II traitedel'enseignement del'économiepolitique en France. $0 \mathrm{n}$ est moins frappé par la critique du libéralisme des professeurs d'économie que de ce qui apparaît aujourd'hui comme le plus évident dans les difficultés de la profession, à savoir la critique du manque de dial ogue entre les économistes ingénieurs et les professeurs d'économie politique des facultés de droit. L'auteur déplore notamment que ces derniers ignorent les innovations majeures apportées au XIXe siècle par D upuis et Cournot. Le troisième texte est un rapport à la commission d'action morale et sociale de l'Egl ise protestante en 1904 et traite des sans-travail à une époque où la caté gorie statistique de chômeur n'existe pas encore. Lequatrième texte de 1911 est un appel à la prise de conscience des équilibres démographiques: «Prenons garde! A I'arrêt dela natalitécorrespond l'arrêt de la richesse française. » L'école française de démographie reprendra avec Landry et Sauvy cet appel dans les années 30 , après la mort de Charles $\mathrm{G}$ ide. Trois textes traitent ensuite de la production et du profit, un autre du sionisme face à la propriété foncièreet un autreencorede I'H omo oconomicus.

Intitulé «Autour del'économie», cet ensemble de textes n'achève pas le contenu de la deuxième partie: deux documents s'y ajoutent. Le premier regroupe dix-neuf textes sur le protectionnisme dont la publication sétale entre 1887 et 1899. C ela fournit un panorama suggestif des débats très chauds à ce tournant de la politique économique française du libre échange au protectionnisme. Le second document s'attache aux débuts de l'histoire de I'U RSS. Commeson neveu, l'illustrissime AndréG ide, l'auteur a fait son voyage en Russie. II s'y attache aux questions agricoles et agraires, à la propriété, au salariat, à la monnaie ainsi qu'aux coopératives, sans oublier de donner ses impressions sur la vie russe.
La troisième partie conclut l'ouvrage par quelques textes plus personnels qui révèlent la qualitéexceptionnelle de l'homme qu'était Charles $\mathrm{Gide.}$ Auteur avec Charles Rist d'une H istoiredes doctrines économiques depuis les physi ocrates jusqu'à nosjoursqui a forméleséconomistes dema géné ration, je ressens comme une œuvre de justice la réalisation de cette édition des œuvres de Charles Gide qui honore la valeur de sa contribution personnelle à cette histoire.

\section{Hugues Puel}

\section{L'économie sociale entre informel et formel Paradoxes et innovations}

Annie Dussuet etJ ean-Marc Lauzanas (dir.). Presse universitaires de Rennes, 2007.

Le soutien de la Délégation interministérielleà l'économie sociale (DIES, devenue DIIESES) ne se limite pas à un aspect financier ou à une reconnaissance institutionnelle. Le programme de recherche que la délégation a lancéen 2004 a en effet permis la publication de nombreux travaux universitaires. Cet ouvrage collectif en témoigne.

Les contributions réunies dans ce livre portent sur sept domaines appliquésà un territoire, l'ouest de la France: le soutien et l'accompagnement à la création d'entreprise, la miseen place de réseaux territoriaux de l'économie sociale, les services aux familles, le tourisme associatif, la finance solidaire, l'environnement et le sport.

\section{Les marchés de services}

Annie D usset et Jean-M arc Lauzanas précisent dansl'introduction quel'ouvrage sintéresse « plus particulièrement aux périodes de transition ou de ruptureoccasionnéeslorsdu passaged'activitésencore informellesà desactivitésdeplusen plusformelles», ainsi qu'àl'implication des organisations del'ES dans cette dynamique. Selon les coordinateurs, " poser la question de la contribution des organisations de l'économie sociale à la construction de marchés deservices, c'est donc essayer de comprendre comment elles utilisent les ressources spécifiques 